\title{
Are the walls giving way to fences? Is racial integration within Kwadukuza municipality leading to income-based class segregation?
}

\author{
Vishanth Singh ${ }^{1}$, Amanda van Eeden ${ }^{2}$ \\ ${ }^{1}$ Geography Division, Statistics South Africa, Pretoria, South Africa and \\ ${ }^{1}$ Department of Geography and Environmental Studies Centre for Regional and Urban \\ Information and Statistical Exploration, University of Stellenbosch, Stellenbosch, South Africa \\ ${ }^{2}$ Department of Geography and Environmental Studies, Centre for Regional and Urban \\ Information and Statistical Exploration, University of Stellenbosch, Stellenbosch, South Africa, \\ avaneeden@sun.ac.za
}

DOI: $\underline{\text { http://dx.doi.org/10.4314/sajg.v6i3.14 }}$

\begin{abstract}
The racial and development imbalances created by apartheid have made a profound impact on the urban and social landscape in South Africa. Despite it being 20 years into the dawn of a new South Africa, many parts of society are still bearing the brunt of the harsh impacts of apartheid. The first democratic elections in 1994 heralded a new era of hope and optimism for a better life in a racially integrated country. However 20 years into democracy, it is essential to monitor changes in integration. Literature suggests that, in the absence of legally enforced segregation as with apartheid, society will segregate itself on class or other factors. The purpose of this study is to measure whether the changes in racial integration are leading to class-based segregation in KwaDukuza, South Africa. The Neighbourhood Diversity Index was used to investigate how the racial patterns changed over the years and a Geographic Weighted Regression (GWR) model was used to determine if there is a relationship between racial integration and income that could explain transference from racial to classed-based segregation. The study found that low levels of racial integration have taken place but certain areas of the municipality have become increasingly segregated. The GWR model found a positive relationship between income and racial segregation in certain areas. This study further highlights that politicians, decision makers, and town and social planners face a long and socially demanding challenge in redressing past imbalances and promoting integration by breaking down the current trend of class-based segregation.
\end{abstract}

\section{Introduction}

The concept of racial segregation which perceives certain groups of people as being superior or inferior to others is not new to social and academic research. From the Negro, Latino and Whitebased segregation in the United States, to caste-based class segregation in India and apartheid's racial segregation in South Africa, the concepts of segregation and integration have been the subject of many studies over the years. 
South Africa is a historically divided country. Harrison, Todes and Watson (2010) indicate that when South Africa emerged from its history of colonialism and apartheid in 1994, its society was characterised by spaces of inequality and division. The South African urban landscape was largely influenced by the introduction of British town planning practices, policies and regulations that aimed to control, prevent and restrict the movement of the Black population into urban areas (Harrison et al., 2010). Although policies such as the Housing Act of 1920 and the Slums Act of 1934 were racially neutral, they supplemented the racially specific Natives Land Act of 1913, Native Urban Areas Act of 1923, the Group Areas Act of 1950, the Population Registration Act of 1950 and the Black Authorities Act of 1951 (Christophe3r, 2001; Maharaj and Mpungose, 1994; Harrison et al., 2010). The latter two pieces of legislation were the primary driving forces that enforced racial segregation and racial zoning in South Africa. By controlling the movement and living spaces of the Black, Coloured and Indian race groups, apartheid policies placed particular burdens on separate levels of development and growing inequality between the Black, Coloured and Indian zoned areas whilst the White racially zoned areas benefited from modern planning methods, better services and facilities. It can thus be stated that the previous apartheid policies have left a unique, but prominent spatial impact on the South African landscape.

However, despite the demise of apartheid and the scrapping of legislation that enforced segregation, wide spread racial integration did not take place as was anticipated. Instead, various studies (Horn, 2005; Christopher, 2001; Durrheim and Dixon, 2010; Parry and van Eeden, 2012) suggest that there has been very little racial integration. Instead of integration, a new form of segregation is emerging; one that is dividing society on levels of class and income.

Against this background, the purpose of this paper is twofold, firstly to test how much racial integration actually took place at a local geographic scale over the last 20 years within KwaDukuza Municipality (KDM), and secondly to determine if there is a correlation between racial integration and income levels that could suggest a transference from race-based segregation to class-based segregation.

The paper starts out by providing a brief literature review of the history and measurement of racial segregation. Secondly, it investigates how the racial patterns for KDM have changed over the last 20 years by using the Neighbourhood Diversity Index with data from Census 1996, 2001 and 2011. Thirdly, a Geographic Weighted Regression (GWR) model is used to determine if there is a correlation between racial integration and levels of income. The paper then concludes with a summary of the research contributions and directions for future research.

\section{Segregation perspective}

The history of racial segregation around the world and particularly in South Africa, has been well documented by the likes of Franklin (1956), Christopher (2001), Crankshaw (2008), Durrheim and Dixon (2010) and Parry and van Eeden (2012) and no doubt many others. Massey and Denton 
(1988:282) define racial segregation as "the degree to which two or more groups live separately from one another, in different parts of the urban environment.”

The apartheid system gradually began to die during the late 1980s and it was officially ended in the early 1990s. However, racial segregation remains a reality in South Africa (Durrheim and Dixon, 2010). People of the same race still tend to cluster together. In their study, Durrheim and Dixon indicate that although people agree to integration in principle, in practice it is the opposite. This difference between the principle support of integration and then opposing it in practice is known as the "paradox of contemporary racial attitudes, or, the principle implementation gap" (Durrheim and Dixon, 2010:281). And it is because of this paradox that people find new ways to segregate themselves. This is supported by Johnston et al., (2003) who suggest that old methods of segregation are just replaced by new methods of segregation. Class-based segregation is one such measure.

Schwirian (1983) indicates that a change in the current social structure of cities is imminent. Urbanisation and globalisation are eroding traditional family lifestyles. Modern lifestyles are giving rise to a new social form; one that is emerging in terms of social rank and economic status; a society segregated in terms of levels of work, income and social prestige. Pacione (2009) indicates that although the caste system in India has traditionally been used to determine social positions in Eastern societies; Western societies are influenced by social economic status which is largely a measure of society's economic spending power. South Africa is no different. Crankshaw (2008) lends support to this argument by indicating that since the scrapping of apartheid, Blacks in South Africa are free to move to or live wherever they want, provided they can afford to. However, segregation by class, effectively separates the haves from the have nots, those that can pay from those that cannot pay (Santiago and Wilder, 1991; Johnston et al., 2003; Horn, 2005; Freeman, 2009).

The South African situation is furthermore affected by the development of gated communities serving as another source of class-based segregation that could even be seen as an attempt to resist integration (Christopher, 2001). Ballard and Jones (2011) indicate that Eco-security estates and gated communities are both a major source of class-based segregation within the South African context. Since 1994, South Africa has seen a steady increase in the number of gated communities developed in previously exclusive white areas. These areas are the choice of residence for the new middle and upper classes that are moving to gated communities with the control of crime being punted as the major reason thereof (Ballard and Jones, 2011; Breetzke, Landman and Cohn, 2014). However, another function of these eco-security estates and gated communities is to create social exclusion by preventing certain people from gaining access thereto (Roitman et al., 2010, Ballard and Jones, 2011; Breetzke et al., 2014). With their superior purchasing power, elite Whites and elite members of other racial groups are able to invest in these areas, ensuring a solely upper class social grouping of like individuals in the area. Hence, although there is a mixing of races, there is social exclusion in that only those that can afford to live in these areas will locate in these areas. 
It is only through empirical measurement of racial segregation and integration that we can determine the impact democracy has had in a non-racial South Africa, 20 years after apartheid. Many indices have been developed over the years that have been used to measure racial segregation and integration. According to Cortese, Falk and Cohen (1976), Massey and Denton (1988), Christopher (2001), Forest (2005), and Horn (2005) the Index of Dissimilarity as proposed by Duncan and Duncan in 1955 has served as a standard measure of racial segregation over time and across racial integration studies. However since 1976 the index has been criticised with the major disadvantages being that it is a global statistic and only measures segregation between two racial groups at a time (Massey and Denton, 1988; Horn, 2005; Freeman, 2009).

Another index is the Entropy Index (Massey and Denton, 1988; Iceland, 2004; Forest, 2005; Freeman, 2009) for studies involving multiple groups. The Entropy Index, also known as Theil's H or the Information Theory Index, was introduced by Henri Theil in 1972 and is also a measure of evenness that assesses how evenly different groups are distributed across a certain spatial area (Iceland, 2004). Unfortunately the disadvantage is that it assumes an equal distribution of all racial groups across the geographical area (Maly, 2000).

As a result of the above, Maly (2000) proposed the Neighbourhood Diversity Index as an alternative to the Entropy Index. The Neighbourhood Diversity Index assumes that integration at lower levels is influenced by the context and history of the larger area. Hence the index is based on the population of different groups found at a low geographic level compared to those found at the higher geographic level. The advantage of this index is that it considers integration in the local context. It is extremely useful when comparing integration within individual city levels, however, because it depends on the population of low level spatial units in relation to the population of the bigger city unit, it will not be comparable across cities as the population proportions of cities are different (Maly, 2000). The Neighbourhood Diversity Index also makes it possible to identify differences in class composition and is most useful in comparing racial change within suburbs in one particular city. However, the disadvantage is that it is a relatively new index that academics have been slow to adopt; they furthermore prefer to use the earlier indices as it allows for comparisons with earlier studies. Because this study is concerned with geographic units within one municipality only, the Neighbourhood Diversity Index was an appropriate index to apply in measuring racial integration.

Geographically Weighted Regression (GWR) is a well known technique that allows the possibility of producing 'local' regression results (Fotheringham, Charlton and Brunsdon, 2016). The underlying idea of GWR is that parameters may be estimated anywhere in the study area given a dependent variable and a set of one or more independent variables which have been measured at places whose location is known (Brunsdon, Fotheringham and Charlton, 1998). GWR has been used to model local variations of residential segregation in a variety of studies (Levers, Bruckner and Lakes, 2010; Hwang, 2014; Lloyd, Catney and Shuttleworth, 2014) and it is for this reason that 
it was chosen to determine if there is a relationship between racial integration and levels of income in $\mathrm{KDM}$.

\section{Data and methodology}

This study focussed on KwaDukuza Municipality (KDM), the dominant district node and commercial hub of the Ilembe District Municipality (Figure 1). KDM is strategically located on the north coast of KwaZulu Natal. Bordering on the eThekwini municipality, it forms part of the N2 corridor that links Durban with Richard's Bay (Integrated Development Plan, 2016). The strategic location is enhanced by the municipality's location between the harbour ports of Durban and Richard's Bay, as well as its close proximity to the King Shaka International Airport and the Dube Trade port.

The municipality consists of the towns of Ballito, Shakaskraal, Groutvisflle, KwaDukuza (formerly Stanger) and Darnall, and has places of strong historical, cultural and tourism links. There are a number of eco-security estates and gated communities in KDM as referred to by Christopher (2001) and Ballard and Jones (2011). These include the likes of Princess Grant, Royal Palm Estates, Simbithi Eco-Estate and the Zimbali Coastal Resort.

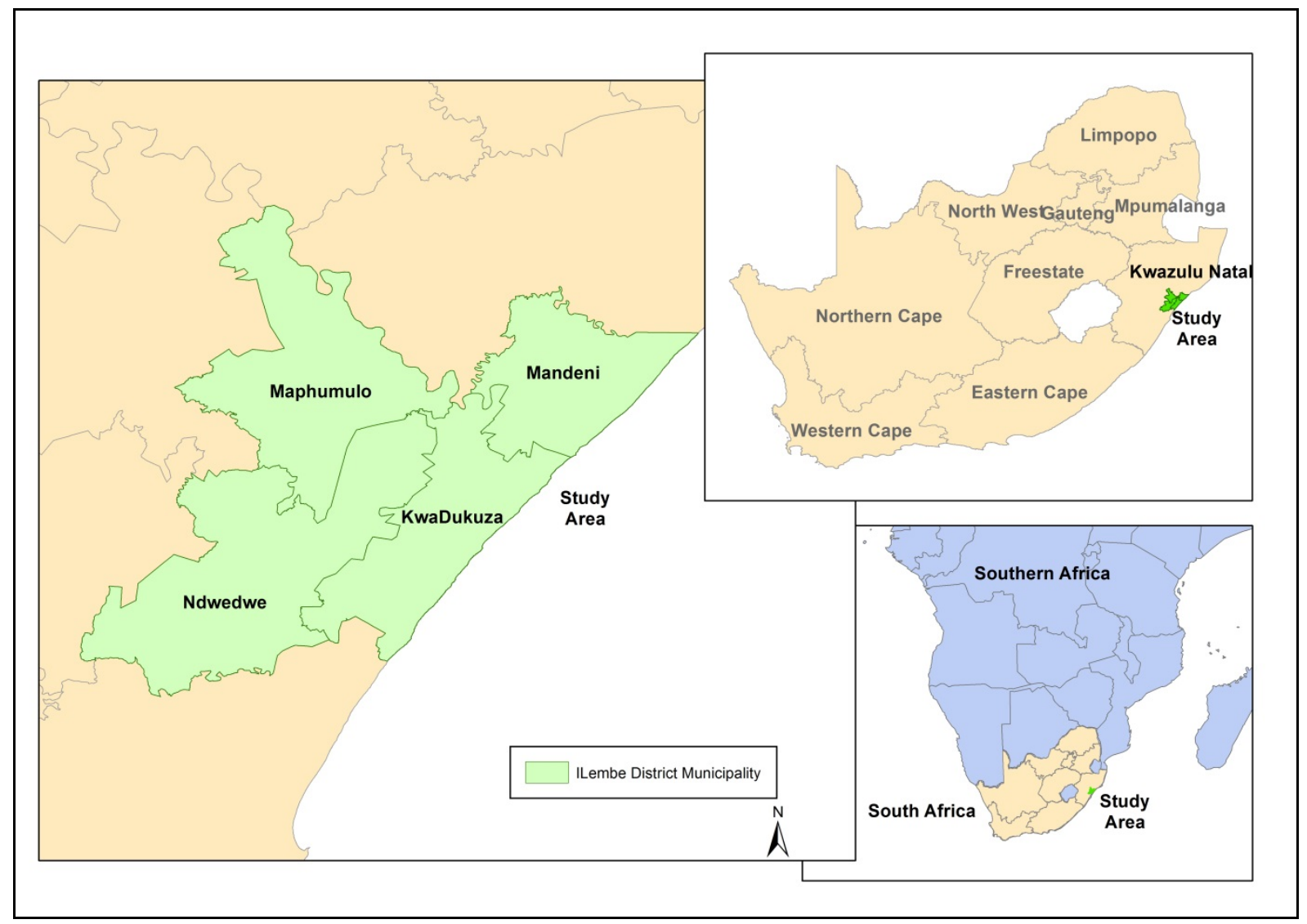

Figure 1: Locality map of ILembe District Municipality showing local municipalities 


\subsection{KDM demarcation and boundary changes}

Friedman (2008) pointed out the difficulty that changing boundaries pose to studies of racial integration over time. KDM is no exception. In work on racial segregation and neighbourhood racial integration in metropolitan America, Friedman (2008) highlighted the importance of using standardised geographical boundaries in order to make comparisons over time.

This study standardised on the 2011 KDM boundary. Statistics South Africa provided the spatial boundary files that ensured that the EA boundaries of 1996, the SAL boundaries of 2001, and 2011 fit within the KDM boundary of 2011. This ensured that data was suitable to allow for a comparison of census information over time.

For Census 1996, EAs were the lowest geographical units at which results were disseminated. However, due to the confidentiality clause in the Statistics Act of 1999, it was no longer possible to disseminate results at an EA level for subsequent censuses. In order to disseminate results at a low geographical unit, a Small Area Layer (SAL) was created. The SAL is a combination of one or more EAs that were aggregated.

\subsection{Data sources and analytical methods}

The main data sources used for the study were population race group and individual monthly income data extracted at EA level for Census 1996, and at SAL level for Census 2001 and Census 2011. The number of census tracts used in the study was 282, 179, and 351 for Census 1996, 2001 and 2011 respectively. The figures differ due to changes in the municipal boundary in the various years, however the aggregated data from Stats SA ensured that the data was comparable.

Two different data analysis methods were used in this study. Firstly the Neighbourhood Diversity Index made use of the population data as an input to calculating racial integration. Secondly, a Geographic Weighted Regression (GWR) used income data to determine the relationship between racial integration and different income classes.

Because this study is concerned with geographic units within one municipality only, the Neighbourhood Diversity Index (ND) was an appropriate index to apply in measuring racial integration. The formula used is:

$N D=1 / 2(|C w-T w|+|C b-T b|+|C c-T c|+|C a-T a|)$

Where: $\quad \mathrm{C}$ is the racial percentage of the city;

$\mathrm{T}$ is the racial percentage of the census unit;

w represents White population;

b represents Black population;

c represents Coloured population;

a represents Indian population; 
|| absolute value notation

The results from the ND index were mapped thematically to show patterns and trends in racial integration within KDM over the three time periods (1996, 2001 and 2011).

When aiming to distinguish between different social classes, scholars have used a variety of combinations of indicators such as income, education, occupation and employment (Farley, 1977; Schwirian, 1983; Santiago and Wilder, 1991; Morrill, 1995; Iceland and Wilkes, 2006; Freeman, 2009). As income is the common indicator across most class-based studies, this study will make use of individual monthly income as a way to measure class.

To determine the relationship between racial integration and individual monthly income, an ESRI ArcGIS GWR model was used. GWR was chosen as it is a local model and performs a regression for each feature in the dataset. The results from the ND index was used as the dependent variable whilst the percentage individuals per income category was used as the independent variable in the GWR model. The output of the GWR model is a R2 value that ranges from $0-1$. R2 values that are close to 1 imply a positive relationship between the two variables and that an increase in the independent variable will result in an increase in the dependent variable.

\section{Data interpretation and results classification}

Maly (2000) identified three categories of integration in the ND index, namely; integrated, moderately integrated, and segregated. These categories were based on the median as they were seen to reflect good units of central tendency and as they reflected the overall environment without being influenced by outliers or anomalies (Maly, 2000). If the results of the ND Index are sorted in ascending order, the areas that had $0 \%$ - 25\% less than the median were considered integrated, the areas between $26 \%$ - $50 \%$ of the median were considered moderately integrated, whilst the areas above the median were considered as segregated (Maly, 2000). As the segregated category was so large, it was expanded, for this study, to include two categories of segregated; namely being moderately segregated (51\% - 75\% of the median) and segregated ( $76 \%-100 \%$ of the median). Although this classification presents similar results as the three category classification, there is a distinct split between the segregated and moderately segregated areas.

With regards to income, Freeman (2009) used four categories of income (poor, working class, middle class and affluent) as determined in relation to the poverty line. However, given the huge income disparities that exist, income distribution in South Africa does not follow a linear pattern but rather an exponential one (Statistics South Africa, 2014). Therefore, using such a liner based classification as suggested by Freeman will not be a true reflection of income-based classes in South Africa. 
Although there is a lack of consensus on how to split up income categories into different classes, economic literature suggests that those individuals earning a per capita income of between R1400 and R10 000 per month (based on 2008 prices) can be regarded as middle class (Visagie, 2013). Assuming a 15\% year on year increase from 2008 to 2011 the above can be adjusted and rounded off to define the South African middle class as those individuals with per capita incomes between R2500 to R17000 (assumed adjustment to 2011 prices). Using Freeman's classification terms with the adapted definition of middle class according to Visagie (2013), the closest Census 2011 income categories were aggregated as follows; Poor (R1 - R800), Working class (R801 - R3200), Middle class (R3201 - R25600), and Affluent (R25601 and more).

\subsection{Calculating the Neighbourhood Diversity Index 1996 - 2011}

The year 1996 marked two years into the dawn of democracy in the new South Africa. Racial integration within KDM as depicted using the Neighbourhood Diversity (ND) Index for 1996 at EA level is shown in Figure 2A. The majority of the segregated areas in 1996 remained in the former Transitional Local Council (TLC) areas. These areas contained suburbs that were directly impacted by the apartheid planning policies of separate development and separate living areas. Society may still have been adapting to a multiracial society which could explain the existence of highly segregated areas within the TLC boundaries. In 1996, 76\% of all EAs in KDM contained one dominant population group that contributed $70 \%$ or more to the total population of that particular census tract.

The EAs that show signs of integration are found immediately outside the TLC boundary and borders on the segregated areas. These integrated areas are the agricultural farming areas of the municipality. Farm owners at the time had farm compounds where accommodation for the farm labourers was provided. Most of the farms are owned by White or Indian families and employ a mixture of Indian and Black labourers, thus showing higher integration levels. 


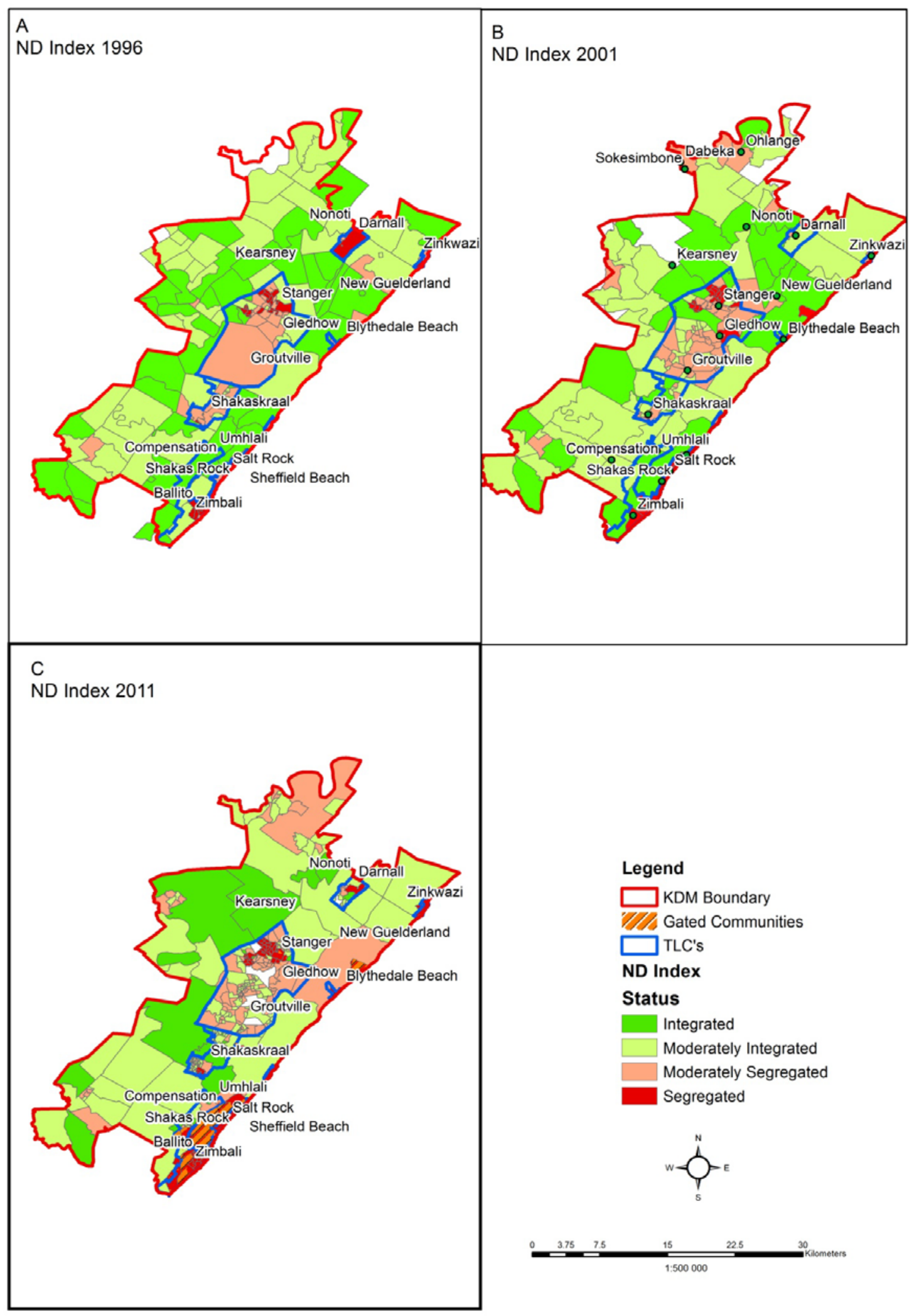

Figure 2: KDM Racial Integration using ND Index

In Fgure 2B the ND index of 2001 was calculated and presents slight but significant changes compared to 1996. Signs of integration are present around the Shakaskraal and Groutville areas as 
well as the northern parts of Stanger. Darnall is now represented as integrated, whereas it was segregated in 1996. Zinkwazi is slightly less segregated, however Princess Grant (immediately northeast of Blythedale Beach) has become more segregated. This is one of many golf security estates that have arisen in KDM over the last 20 years. Notable areas occupied by other estates can be found around Ballito, Zimbali, and Salt Rock. These areas also show signs of increased segregation, confirming the notion by Ballard and Jones (2011) that security estates and gated communities contribute to social exclusion and class-based segregation.

There is the emergence of a cluster of integrated areas that surround the segregated areas near Ballito, places such as Sheffield Beach, Umhlali, and Shakas Rock. As these areas are slightly inland and do not have access to sea views, property prices are cheaper, making the area affordable and accessible to more people, whereas properties along the coast demand high prices due to sea views, thus remaining within the affordability of only the elite. The farms surrounding the former TLC areas still retain much of their integrated status from 1996, whilst the deep rural areas of Dabeka, Ohlange and Sokesimborne found towards the northern boundary of KDM consists of SALs that contain $100 \%$ black population. These areas are thus considered to be segregated.

The ND index for 2011 as shown in Figure 2C paints a sad picture for democracy and the ideals of a racially integrated society. As is evident, KDM was much more segregated in 2011 than in 1996 and 2001, implying that 17 years after democracy areas at a SAL scale within KDM have become increasingly segregated as opposed to integrated.

The Ballito, Zimbali and Salt Rock areas remain amongst the highest segregated areas, whilst the previously integrated neighbouring areas near Shakas Rock and Umhlali have also become segregated. This could be because of the rapid increase in the number of security and eco-estates in that part of the municipality which caused an increase in the property prices. Figure $2 \mathrm{C}$ validates the above by displaying the spatial locations of these gated communities. Other coastal areas such as Tinely Manor Beach, Blythedale Beach and Zinkwazi have also become highly segregated. As with the other coastal areas, the increased property values in these areas have made them accessible only to a certain elite.

Other major changes are noted within the former Stanger TLC where SALs have become more segregated and those that were integrated have moved into moderately integrated. The SALs around Groutville remain mostly segregated, interspersed with patches of integrated SALs. Although the agricultural areas adjacent to the TLC are still integrated, most of these areas have moved from integrated to being moderately integrated. The deep rural areas towards the northern boundary are showing increased signs of segregation with the Indian population in the area dropping from $6 \%$ to just over $1 \%$ whilst the White population was a mere $1 \%$ in 2001 and $0.6 \%$ in 2011. The SAL between New Guelderland, Blythedale Beach and bordering the former Stanger TLC, has seen a drop in the Black population from $75 \%$ in 2001 to $44 \%$ in 2011 . In a similar fashion it has seen an increase in the Indian population from 25\% in 2001 to 55\% in 2011. This 
change in racial percentages contrasts from the racial average, hence the SAL has now changed from integrated in 2001 to moderately segregated in 2011.

\subsection{The relationship between racial integration and income}

Traditionally the income related questions have been amongst the worst answered questions across censuses. Most respondents are reluctant to answer these questions accurately and either understate their income or indicate no income on the census questionnaire. Within KDM, 38\% of the population indicated that they had no income. However, in the absence of other low level income datasets, the census dataset still remains the best to use for low level income calculations.

The highest percentage of affluent individuals within KDM is found along the coastal areas, particularly around Ballito, Zimbali, Shaka’s Rock and Salt Rock (Figure 3). Other correlations are found in the Royal Palm Estates near Shakaskraal and Princess Grant just north of Blythedale Beach. Blythedale Beach and Zinkwazi also have fairly high percentages of affluent individuals. This corresponds to the segregated coastal areas in Figure 2C. The segregated coastal and affluent areas are predominately occupied by a high percentage of the White population. Noteworthy exclusions occur in the inland areas that are segregated as a result of them being occupied by extremely high percentages of either Black or Indian populations.

In order to understand and determine the relationship between income and racial integration a Geographic Weighted Regression (GWR) model was run. Figure 4 shows the GWR income coefficient for KDM. When a GWR was run using the ND index of 2011 as the dependent variable and the percentage affluent individuals as the independent variable, the resultant R2 value was 0.60. This means that there is a strong positive relationship between the two variables. The percentage of affluent individuals, therefore predicts $60 \%$ of the ND Index, and when the percentage of affluent individuals increases, the ND Index can be expected to increase as well, implying increased segregation. Figure 4A indicates that in the yellow to red areas the percentage of affluent individuals is a strong predictor and plays a greater role in influencing segregation in those areas. This shows a positive relationship with the segregated coastal areas shown in Figure 2C. In the blue areas, the percentage of affluent individuals does not play a significant role in segregation. 


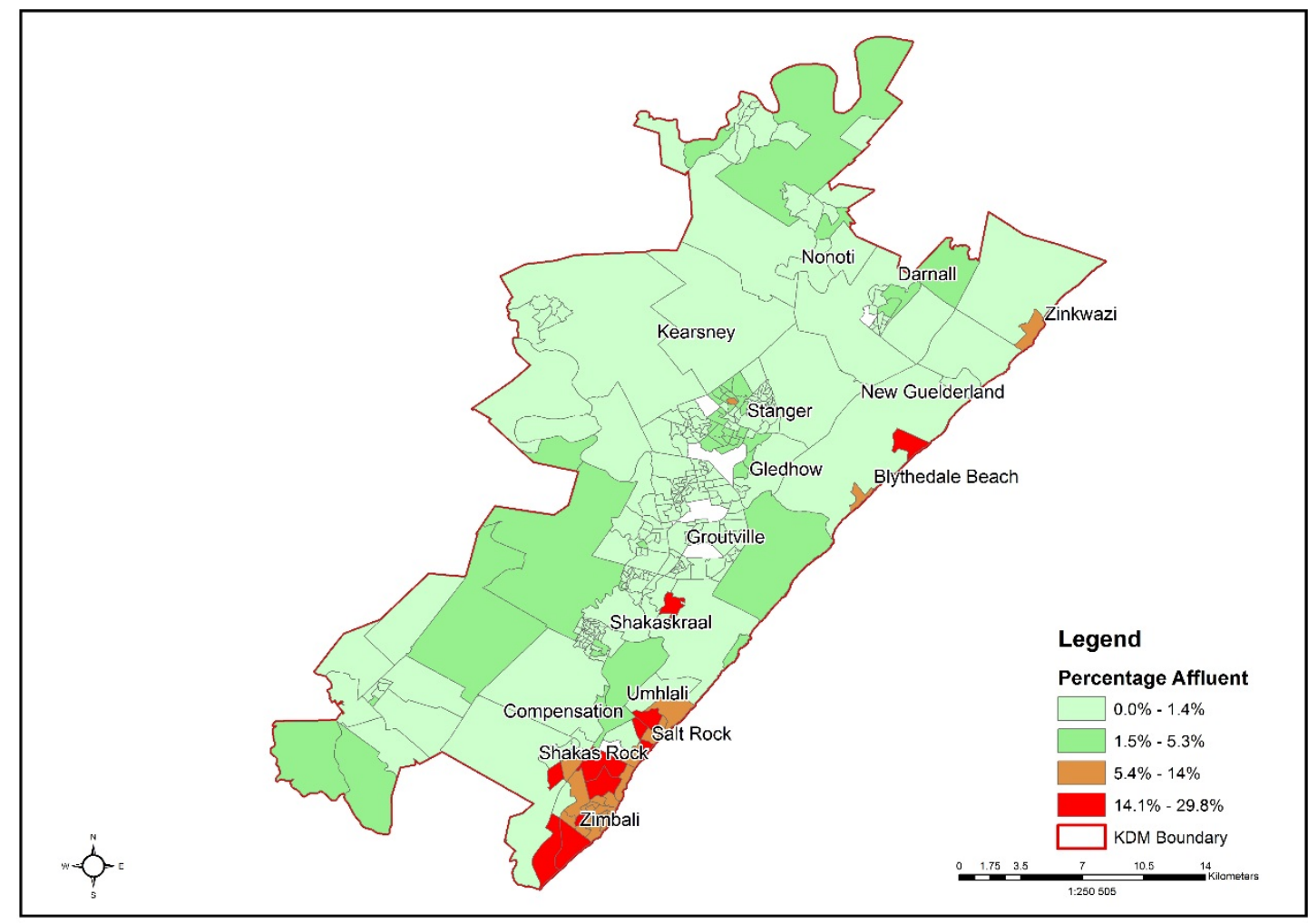

Figure 3: Percentage Affluent Individuals in KDM per SAL, 2011

Questions concerning income are generally not well answered in census questionnaires; furthermore people are reluctant to state their true and correct income, often understating the income earned. This could explain why the model under predicts in the areas surrounding Ballito. An evaluation of the GWR between the ND Index and the percentage of middle-class individuals saw an increase in the $\mathrm{R} 2$ value to 0.66 . This presents a stronger positive correlation than the earlier GWR with a percentage of affluent individuals. Figure 4B presents the GWR intercept between the ND Index and the percentage of middle-class individuals. As per earlier explanation, the red areas are where the percentage of middle-class individuals explain more of the ND Index (level of segregation) whilst the blue areas are where the percentage of middle-class individuals explain less of the ND Index. 


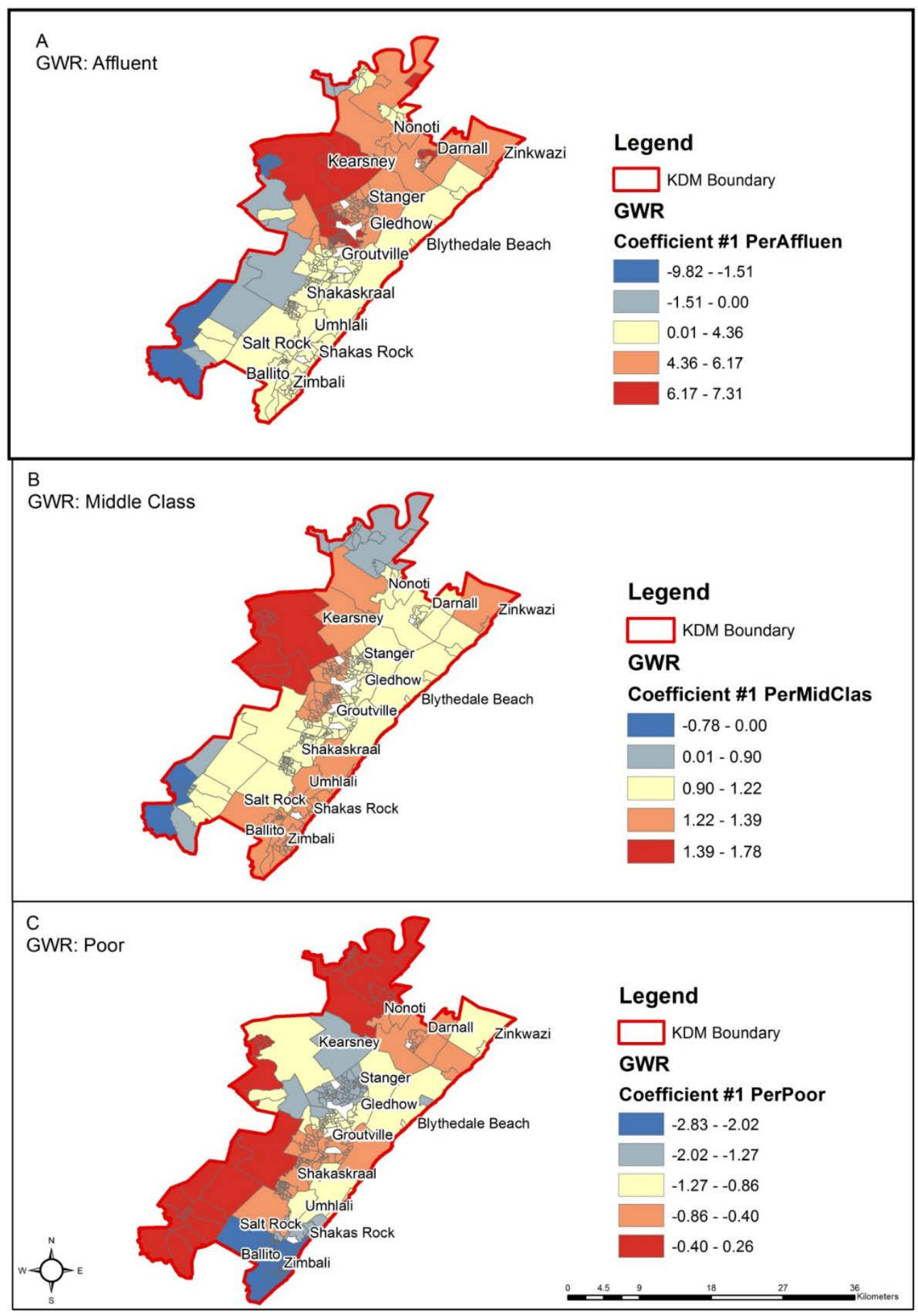

Figure 4: GWR Income Coefficients for KDM.

The R2 results of the GWR for percentage of poor was 0.69 which means that there is positive relationship between the ND Index and percentage of poor individuals. However, due to the sensitivity of the income question, it is likely that a large number of individuals would have understated their income and recorded it as poor. This means that the percentage of poor in the southern coastal areas is a weak predictor of segregation in areas (Figure 4C). In the outlying areas 
along the northern and south-western boundaries of the municipality the percentage of poor people provides explanation strong prediction for segregation.

Although GWRs were also done for the percentage working and percentage of those earning no income the results were inconclusive and therefore not presented. The GWR models presented do prove that there is indeed a significant relationship between racial integration and lower (poor) and upper income levels (middle class and affluent) at a small area level.

\section{CONCLUSION}

The dawn of democracy in South Africa in 1994 ushered in a new era of change with the promise of a non-racial and non-discriminatory society. This study had two main aims. The first was to determine how much racial integration took place over the last 20 years, with KwaDukuza Municipality (KDM). The second was to determine if there is a relationship between racial integration and income levels. In accomplishing these aims, this study makes some important contributions to existing literature on the subjects of racial integration, racial segregation and classbased segregation.

The study found that in a country where one population group dominates the total population with over $70 \%$, an expectation of evenness amongst all racial groups per census tract become unrealistic. As a result of this, the Neighbourhood Diversity Index can be considered a viable alternative to the historic indices of dissimilarity and entropy, as it considers the racial composition of each census tract in relation to the municipal racial composition.

The literature also suggests that society will be segregated along various different forms as people with similar characteristics will tend to stick together. With the removal of apartheid legislation people can no longer be legally segregated along racial lines; however, there may be a possible transference from race-based segregation to class-based segregation in terms of affordability and income that is becoming the new defining feature in, segregating South African society. Thus, although the walls of apartheid have fallen, new barriers or fences of segregation along income or class lines have risen.

The findings of this study confirm suggestions in existing literature that low levels of racial integration have taken place on a small area level within KDM, particularly in the agricultural and small holding areas which are also the areas immediately bordering the former TLC areas. However the coastal areas of the municipality which are also home to numerous eco-estates and security estates have become increasingly segregated over the last 20 years. As a result KDM as a whole remains largely segregated despite 20 years of democracy.

This study is perhaps the first that specifically tries to correlate racial integration as measured with the ND Index, with income levels established through census questionnaires. The GWR 
models that were run showed a strong positive relation between the ND Index and affluent, middle and poor individuals at a SAL.

This study highlights that the politicians, decision makers, town planners and social planners still face a long and socially demanding challenge in implementing policies and programmes that aim to target the integration challenges as posed by the NDP. Class-based segregation has created major sociocultural and economic inequalities at a local level. Those within the upper income residential areas will attract economic growth and developments due to their higher spending power. There is therefore still a long way to go in redressing past imbalances and promoting integration by breaking down the current fences of class-based segregation.

\section{REFERENCES}

Ballard R and Jones GA 2011, Natural neighbours: Indigenous landscapes and Eco-Estate in Durban, South Africa, Annals of the Association of American Geographers, vol.101, no. 1, pp. 131-148.

Breetzke GD, Landman K and Cohn EG 2014, Is it safer behind the gates? Crime and gated communities in South Africa, Journal of Housing and the Built Environment, vol. 29, pp. 123-139.

Brunsdon C, Fotheringham S and Charlton M 1998, Geographically Weighted Regression, Journal of the Royal Statistical Society: Series D (The Statistician), vol. 47, no 3, pp.431-443.

Christopher AJ 2001, Urban Segregation in Post Apartheid Society, Urban Studies, vol. 38, no. 6, pp. 449-466.

Cortese CF, Falk RF and Cohen JK 1976, Further considerations on the methodological analysis of segregation indices, American Sociological Review, vol. 41, no. 4, pp. 630-637.

Crankshaw O 2008, Race, Space and the Post Fordist Spatial Order of Johannesburg, Urban Studies, vol. 45, no. 8, pp. 1692-1711.

Duncan OD and Duncan B 1955, A methodological analysis of segregation indexes, Sociological Review, vol. 20, no. 2, pp. 210-217.

Durrheim K and Dixon J 2010, Racial contact and change in South Africa, Journal of Social Sciences, vol. 66, no. 2, pp. 273-288.

Farley R 1977, Residential Segregation in Urbanized Areas of the United States in 1970: An Analysis of Social Class and Racial Difference, Demography, vol. 14, no. 4, pp. 497-517.

Forest B 2005, Measures of Segregation and Isolation. Dartmouth College, viewed 12 December 2015, < http://www.dartmouth.edu/ segregation/IndicesofSegregation.pdf $>$.

Fotheringham AS, Charlton ME, Brunsdon C 2016, Geographically Weighted Regression: A Natural Evolution of the Expansion Method for Spatial Data Analysis, Environment and Planning A, vol. 30, no. 11, pp. 1905-1927.

Franklin JH 1956, History of Racial Segregation in the United States, Annals of the American Academy of Political and Social Science vol. 304, pp.1-9.

Freeman L 2009, Neighbourhood Diversity, Metropolitan Segregation and Gentrification: What are the links in US? Urban Studies, vol. 46, no. 10, pp. 2079 - 2101.

Friedman S 2008, Do declines in racial segregation mean stable neighbourhood racial integration in metropolitan America? A research note. Social Science Research, vol. 37, pp. 920-933. 
Harrison P, Todes A and Watson V 2010, Planning and Transformation: Learning from the PostApartheid experience, Routledge, London.

Horn A 2005, Measuring multi ethnic spatial segregation in South African cities. South African Geographical Journal, vol. 87, no. 1, pp. 58-72.

Iceland J 2004, The Multigroup Entropy Index (Also Known as Theil's H or the Information Theory Index). United States Census Bureau, viewed 15 November 2015, $<$ http://www.census.gov/hhes/www/housing/resseg/multigroup_entropy.pdf>.

Iceland J and Wilkes R 2006, Does Socioeconomic Status Matter? Race, Class and Residential Segregation, Social Problems, vol. 53, no. 2, pp. 248-273.

Integrated Development Plan 2016, KwaDukuza Municipality 2016-2017 Integrated Development Plan, viewed $06 \quad$ June 2017, http://www.mile.org.za/Intermediary\%20Cities/Documents/KwaDukuza\%20IDP\%202012-17.pdf.

Johnston R, Poulsen M and Forrest J 2003, And Did The Walls Come Tumbling Down? Ethnic Residential Segregation In Four US Metropolitan Area 1980 - 2000 Urban Geography, vol. 24, no. 7, pp. 560-581.

Levers C, Brückner M, Lakes T 2010, 'Social segregation in urban areas-an exploratory data analysis using geographically weighted regression analysis', Paper presented at the 13th AGILE International Conference on Geographic Information Science, May 2010, Guimaraes, Portugal.

Lloyd CD, Catney G, Shuttleworth IG, 2014, 'Measuring neighbourhood segregation using spatial interaction data', in CD Lloyd, IG Shuttleworth, DW Wong(eds.), Social-spatial segregation: Concepts, processes and outcomes, Policy Press, Bristol.

Maharaj B and Mpungose J 1994, The Erosion of Residential Segregation in South Africa: The Greying of Albert Park in Durban, Geoforum, vol. 25, no. 1, pp. 19-32.

Maly T 2000, The Neighbourhood Diversity Index: A Complementary Measure of Racial Residential Settlement, Journal of Urban Affairs, vol. 22, no. 1, pp. 37-47.

Massey DS and Denton NA 1988, The dimensions of racial segregation. Social Forces, vol. 67, no. 2, pp. 281-315.

Morrill R 1995, Racial Segregation and Class in a Liberal Metropolis. Geographical Analysis, vol. 27, no. 1, pp. 22 - 44.

Pacione M 2009, Urban Geography, A Global Perspective. Routledge: New York.

Parry K and van Eeden A 2012, Measuring racial segregation at different geographic scales in Cape Town and Johannesburg, South African Geographical Journal, vol. 97, no. 1, pp. 31-49.

Roitman S, Webster C and Landman K 2010, Methodological Frameworks and Interdisciplinary Research on Gated Communities, International Planning Studies, vol. 15, no. 1, pp. 3-23.

Santiago AM and Wilder MG 1991, Residential Segregation and Links to Minority Poverty: The Case of Latinos in the United States, Social Problems, vol. 38, no. 4, pp. 492-515.

Schwirian KP 1983, Models of Neighbourhood Change, Annual Review of Sociology, vol. 9, pp. 83- 102.

Statistics South Africa 2014, Poverty trends in South Africa: An examination of absolute poverty between 2006 and 2011, Statistics South Africa Report-03-10-06, Pretoria, view 8 September 2014, $<$ http://www.statssa.gov.za/publications2/statsabout.asp?PPN=Report-03-10-06\&SCH=>.

Visagie J 2013, Race, Gender, and the Growth of the Affluent Middle Class In Post Apartheid Society, Paper presented at the Biennial Conference of the Economic Society of South Africa $25-27$ September 2013. University of Free State. Bloemfontein. 